\title{
The TUCAN3G project: Wireless technologies for isolated rural communities in developing countries based on 3G small-cell deployments
}

\author{
Andrés Martínez-Fernández, Rey Juan Carlos University \\ Josep Vidal, Universitat Politècnica de Catalunya \\ Javier Simó-Reigadas, Rey Juan Carlos University \\ Ignacio Prieto-Egido, EHAS Foundation \\ Adrián Agustín, Universitat Politècnica de Catalunya \\ Juan Paco, Pontifical Catholic University of Peru \\ Álvaro Rendón, Cauca University
}

Abstract - Recent years have witnessed a massive penetration of cellular systems in developing countries.

However, isolated rural areas (sparsely inhabited by low-income population) have been disregarded because classical access and backhaul technologies do not assure the return on investment. This paper presents innovative techno-economical solutions to provide these areas with cellular voice and data services. We first analyze the general characteristics of isolated rural communities, and based on this information, low cost solutions are designed for both access (using 3G access points (AP)) and backhaul networks (using non-carrier grade equipment as WiFi for long distances (WiLD) or WiMAX in non-licensed bands). Subsequently a study of population-dependent income versus costs is presented and a new business model is proposed involving mobile network operators (MNO), rural operators and infrastructure providers. In order to test these solutions, we have built two demonstration platforms in the Peruvian jungle which have allowed validating the technical feasibility of the solution, verifying the business model assumptions and the scalability of the initiative.

\section{INTRODUCTION}

According to data provided by the ITU, the mobile broadband market is the most dynamic in the telecommunications industry. It is estimated that, at the time of writing, $89 \%$ of the world's urban population has $3 \mathrm{G}$ (or LTE) coverage. However, the situation is different for rural population: only $29 \%$ will have $3 \mathrm{G}$ coverage on the same date [1]. 
Focusing on developing countries (DC), only $34 \%$ of households have Internet access (in the least DC, the percentage is only $7 \%$ ), in contrast to $80 \%$ in the developed world. This means that over 4 billion people are not yet connected to the Internet. Moreover, a significant number of African countries still do not report mobile broadband coverage in rural areas. As a way of example, in Guatemala an urban citizen is 12 times more likely to have Internet connectivity than a rural inhabitant. Differences are far from reducing: in Colombia, the difference between rural and urban dwellers has raised from 18\% to 35\% between 2009 and 2012 [2].

The challenge of connecting rural areas is not trivial. Classic infrastructures, requiring costly cell towers and satellite or optical backhaul, are not suitable. Only decisive actions from the administration (promoting or even fully funding rural infrastructure) and regulatory offices (extending the concept of universal service, creating new figures for rural MNOs or relaxing the quality-of-service requirements in rural areas), may generate enough motivation to push researchers, equipment manufacturers and MNOs towards rural inclusion.

Recent works have proposed very interesting bottom-up strategies (based on community initiatives) to expand voice services in rural areas through technologies such as OpenBTS [3], a combination of OpenBTS with WiFi [4], or WiFi mesh networks [5]. However, rural communities not always have the knowledge, the legal capacity or the resources to deploy those technologies. This paper presents the approach adopted by the project TUCAN3G (funded by the European Commission), that proposes technically feasible and yet economically sustainable solutions for the progressive introduction of voice and broadband data services in small communities of rural areas of DC, using conventional 3G cellular terminals.

\section{TECHNICAL AND SOCIOECONOMIC OBJECTIVES}

TUCAN3G proposes the introduction of $3 \mathrm{G}$ APs in outdoor environments, with heterogeneous backhauling in unlicensed bands using WiFi for Long Distances (WiLD) [6] and WiMAX, to provide profitable mobile services to remote rural areas of DC. The project was structured around three distinct pillars considered as key for the development of a viable solution: 
- Study of the technical feasibility of QoS-ensuring access and transport solutions, adopting low cost, low power consumption technologies (the only source of power is solar panels) that facilitate the scaling up when the demand grows.

- The elaboration of a comprehensive and sustainable business case study based on a market survey which focuses on analyzing three key areas: service demand, cost of technology (split in CAPEX and OPEX) and financing models (including mixed public-private).

- Demonstrative pilot. The project deployed two networks that provide 3G services in the Department of Loreto, Peru. These networks validate in a real scenario the technology developed, and allow empirically testing the hypotheses of the proposed business model.

\section{RuRal SCEnARIo AND USE CASES}

The TUCAN3G project searches global solutions that can be applied to most rural areas in DC. To attain that goal, the Peruvian case is highly representative because three clearly identifiable regions are encountered: the Coast (highly populated and well connected), the Highland (poor and with some connectivity issues) and the Jungle (flat terrain covered by the Amazon rainforest, with a very low population density and with very serious problems of connectivity). While almost $50 \%$ of the urban population uses the Internet, only $11 \%$ of the rural population does. $30 \%$ of urban households have Internet access while only $1 \%$ of rural households have it [7].

We can observe in Figure 1-left the mobile service cells deployed in the country (small circles). Most of the populated locations (in brown) located in the forest departments (in green in Figure 1-right) lack of cellular coverage. Similar conditions are found in the Highlands. The correlation between cellular coverage and roads in rural areas is almost perfect, as shown in Figure 1. It is straightforward to conclude that unconnected locations correspond to low-income sparse rural population that also lack electricity supply and roads.

We focus on two regions in the Amazon forest, as worst cases from the point of view of access to telecommunications. One is along the Napo River, and the other one is in Balsapuerto, along the Paranapura River, both in the Department of Loreto (Figure 1). 

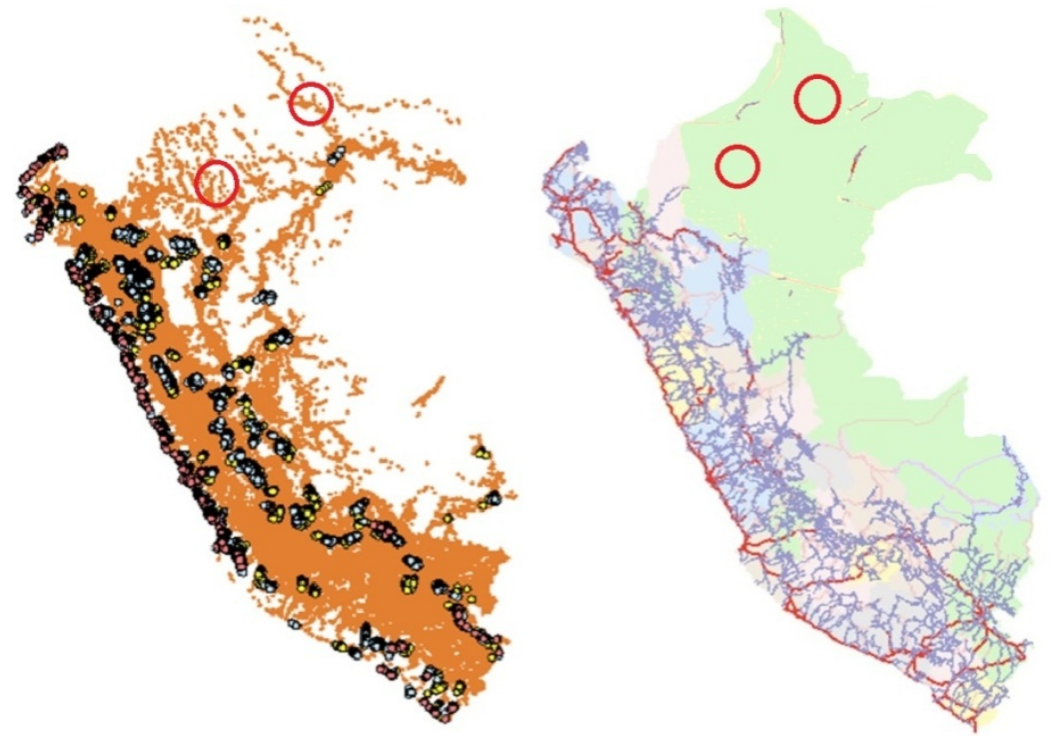

Figure 1. Base stations (left) and roads network (right) in Peru [adapted from MTC-Peru]. Red circles show the positions of the demonstrative platforms deployed by TUCAN3G.

\section{Network Design Challenges And Solutions}

\subsection{ACCESS NETWORK}

TUCAN3G has departed from a traffic model provided by Telefonica del Peru (TdP) in rural areas in Peru in which $10 \mathrm{mErl}$ per inhabitant are generated at the peak hour. As for the long-term traffic evolution, TUCAN3G considers a traffic increase of $180 \%$ in the second year of service, followed by $5 \%$ in the third year and $2 \%$ in the fourth and fifth years. Covering these traffic demands, and being low-cost, low-power consumption, has led to the selection of 3G RAN low output power AP, which provide the adequate coverage, and require simpler installation than large base-stations. This solution implies low CAPEX and allows a progressive deployment when demand increases. The approach adopted addresses several questions:

Energy provision. The power consumption of micro base stations is around $100 \mathrm{~W}$, while pico and femto AP have around $10 \mathrm{~W}$ and $5 \mathrm{~W}$, respectively [8]. The energy dimensioning for the different sites has been calculated assuming commercial batteries (Ritar 12V 100Ah) and solar panels (Solar World 85W/panel) under the worst case assumption that each small cell should work up to $24 \mathrm{~h}$ at full power during 3 days without solar radiation. The energy elements required per site appear in Table I. 
Coverage area. Femto APs are suitable for outdoor scenarios if they are placed in high position and can take advantage of line-of-sight propagation. Additionally, wooden walls constructions create reduced path losses in outdoor-to-indoor channels. In those conditions, the APs deployed in the $800 \mathrm{MHz}$ band licensed in Peru are able to reach a coverage area up to $2 \mathrm{~km}$. The communities are placed 20-70 km apart, so interference is negligible.

Number of APs needed. The communities considered generate low traffic and the population is fairly concentrated, so one or two $3 \mathrm{G}$ AP of 16 (or 24) channelization codes collocated in the same tower at high position are typically enough. The second AP is required to satisfy peak traffic demands in some scenarios, and operates at a different frequency. The network planning and energy provision dimensioning results are shown in Table I.

Table I. Access network parameters for the two networks deployed in TUCAN3G

\begin{tabular}{|c|c|c|c|c|c|c|c|c|c|}
\hline & Community & $\begin{array}{l}\text { APs from } \\
\text { ip.access }\end{array}$ & $\begin{array}{l}\text { Anten } \\
\text { configur }\end{array}$ & na & $\begin{array}{c}\text { Solar panel } \\
\text { units } \\
\left(P_{n o m}=85 \mathrm{~W}\right)\end{array}$ & $\begin{array}{c}\text { Battery units } \\
(C=1200 \mathrm{Ah} \times \mathrm{V})\end{array}$ & $\begin{array}{c}\text { Backhaul DL } \\
\text { in year } 5\end{array}$ & $\begin{array}{c}\text { Backhaul } \\
\text { UL in year } 5\end{array}$ & $\begin{array}{c}\text { Inhabitants } \\
\text { including people } \\
\text { in itinerancy }\end{array}$ \\
\hline \multirow{4}{*}{ 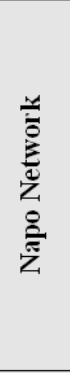 } & $\begin{array}{c}\text { Santa Clotilde } \\
2^{\circ} 29^{\prime} 22.40^{\prime \prime} \mathrm{S} \\
73^{\circ} 40^{\prime} 40.70^{\prime \prime} \mathrm{W} \\
\end{array}$ & 2 S-Class 16 & $\begin{array}{l}\text { Gain: } \\
\text { Downtilt: } \\
\text { Height: }\end{array}$ & $\begin{array}{c}7 \mathrm{~dB} \\
10^{\circ} \\
70 \mathrm{~m}\end{array}$ & 3 & 3 & $1872 \mathrm{Kbps}$ & $864 \mathrm{Kbps}$ & 3222 \\
\hline & $\begin{array}{c}\text { Negro Urco } \\
3^{\circ} 01^{\prime} 23.10^{\prime \prime} \mathrm{S} \\
73^{\circ} 23^{\prime} 31.50^{\prime \prime} \mathrm{W}\end{array}$ & 1 S-Class 16 & $\begin{array}{l}\text { Gain: } \\
\text { Downtilt: } \\
\text { Height: }\end{array}$ & $\begin{array}{l}7 \mathrm{~dB} \\
10^{\circ} \\
70 \mathrm{~m}\end{array}$ & 2 & 2 & \multirow{2}{*}{$1238 \mathrm{Kbps}$} & \multirow{2}{*}{$608 \mathrm{Kbps}$} & \multirow{2}{*}{316} \\
\hline & $\begin{array}{c}\text { Libertad } \\
3^{\circ} 1^{\prime} 41.31^{\prime \prime S} \\
73^{\circ} 22^{\prime} 40.14^{\prime \prime} \mathrm{W} \\
\end{array}$ & $1 \mathrm{~S}-\mathrm{Class} 16$ & $\begin{array}{l}\text { Gain: } \\
\text { Downtilt: } \\
\text { Height: }\end{array}$ & $\begin{array}{l}7 \mathrm{~dB} \\
10^{\circ} \\
15 \mathrm{~m} \\
\end{array}$ & 2 & 2 & & & \\
\hline & $\begin{array}{c}\text { Tuta Pishco } \\
3^{\circ} 06^{\prime} 31.40^{\prime \prime} \mathrm{S} \\
73^{\circ} 08^{\prime} 17.50^{\prime \prime} \mathrm{W} \\
\end{array}$ & 2 S-Class 16 & $\begin{array}{l}\text { Gain: } \\
\text { Downtilt: } \\
\text { Height: }\end{array}$ & $\begin{array}{c}7 \mathrm{~dB} \\
10^{\circ} \\
50 \mathrm{~m}\end{array}$ & 3 & 3 & $1066 \mathrm{Kbps}$ & $557 \mathrm{Kbps}$ & 287 \\
\hline \multirow{2}{*}{ 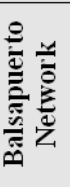 } & $\begin{array}{c}\text { Varadero } \\
5^{\circ} 42^{\prime} 49.99^{\prime \prime} \mathrm{S} \\
76^{\circ} 24^{\prime} 39.59^{\prime \prime} \mathrm{W} \\
\end{array}$ & 2 s-Class 16 & $\begin{array}{l}\text { Gain: } \\
\text { Downtilt: } \\
\text { Height: }\end{array}$ & $\begin{array}{c}7 \mathrm{~dB} \\
10^{\circ} \\
30 \mathrm{~m} \\
\end{array}$ & 3 & 3 & $1987 \mathrm{Kbps}$ & $892 \mathrm{Kbps}$ & 948 \\
\hline & $\begin{array}{c}\text { San Juan } \\
5^{\circ} 52^{\prime} 35.13^{\prime \prime} \mathrm{S} \\
76^{\circ} 21^{\prime} 21.73^{\prime \prime} \mathrm{W}\end{array}$ & 1 E-Class 24 & $\begin{array}{l}\text { Gain: } \\
\text { Downtilt: } \\
\text { Height: }\end{array}$ & $\begin{array}{l}2 \mathrm{~dB} \\
0^{\circ} \\
20 \mathrm{~m}\end{array}$ & 1 & 1 & $562 \mathrm{Kbps}$ & $285 \mathrm{Kbps}$ & 118 \\
\hline
\end{tabular}

Adoption of energy-aware self-optimization techniques. Self-organization techniques enable quick unsupervised network management procedures, which entails little human intervention and reduction of OPEX. In the rural scenarios self-organization implies reconsidering two paradigms usually overlooked in urban wireless cellular networks: i) limited access to energy, and ii) stringent backhaul limitations. First, the integration of the status of the battery and the energy flow from solar panels in self-optimization mechanisms has led to the definition of a switch on-off solution, as a function of the daily traffic demand, which allows a reduction of $20 \%$ in the size of solar panels and batteries [9]. Second, self-allocation of primary sync codes has been implemented. Third, user association techniques: unlike conventional practice, which is based on the user association to the AP received with the strongest pilot signal, battery powered APs require energy-aware constrained association 
[10][11]. Evaluated results indicate significant benefits in terms of bitrate for cell-edge users, improving Jain's fairness index in $30 \%$ with respect to conventional max-SINR criterion.

To account for the limited capacity backhaul, proper design of the access network is needed. Conventional schedulers address the backhaul limitations by imposing a maximum instantaneous rate as a function of the backhaul bandwidth information, which is an average measure and hence it yields an excessively conservative solution. In contrast, TUCAN3G proposes a scheduler that specifically considers the average backhaul state information as a constraint to be satisfied in the long term, in addition to other constrains like the battery status and energy harvesting. This way, the system sum-rate and the fairness can be considerably improved [12], and the system is made robust against energy outages and backhaul congestion. For instance, for a backhaul capacity of $500 \mathrm{Kbps}$, the difference between forcing an instantaneous constraint on the backhaul or taking the constraint in the long-term results in an improvement around $200 \%$ both in the rate of the worst user and in the system sum-rate [13].

\subsection{TRANSPORT NETWORK AND INTERCONNECTION TO THE CORE}

Connection of the access network requires a low cost transport network that ensures QoS and low energy consumption. The cost can be dramatically lowered by sharing part of the backhaul infrastructure among several locations, which in turn generates traffic management issues. Additionally, the use of low-cost technology operating in unlicensed bands can be adopted here for carrier-class deployments due to the low or inexistent interference. In this context, a combination of WiLD [14] and/or WiMAX systems operating in non-licensed bands is a viable solution for a multi-hop heterogeneous backhaul provided that the capacity is sufficiently high and the per-hop delay and packet loss are controlled. The performance of point-to-point links has been theoretically analyzed and experimentally tested, proving that WiLD operating in $20 \mathrm{MHz}$ channels allows capacities over 45 Mbps at $20 \mathrm{~km}$, and over $20 \mathrm{Mbps}$ at $55 \mathrm{~km}$, while keeping the average delay under $5 \mathrm{~ms}$ and a negligible packetloss. WiMAX allows capacities of approximately $60 \%$ of those obtained for WiLD with $10 \mathrm{MHz}$ channels, for the same delay and packet-loss figures [14]. Higher capacities may be achieved under saturation conditions, but at the cost of QoS degradation.

Geostationary satellite links can be contemplated as a solution: they require simple of earth stations and low cost compared to non-geostationary. However, the downsides are the high propagation delay (a round-trip time in 
excess of $500 \mathrm{~ms}$ ) and a recurring expensive monthly cost (around US\$ 3,000 per dedicated Mbps) compared to alternative solutions.

Ensuring end-to-end QoS in multi-hop backhaul infrastructures. The QoS management must be designed in such a way that each AP perceives an acceptable performance regardless of the traffic generated by other AP connected to the backhaul. In this sense, the main hurdle is adjusting the operation point per link in order to avoid saturation and limit delay and packet-loss. Secondly, end-to-end traffic differentiation is a must (i.e. prioritizing voice and signaling traffic over data traffic). Third, it is fundamental to limit the traffic circulating across the multi-hop backhaul so that none of the links saturate. Such traffic limits must be imposed in a distributed way, as the traffic flows in shared links are introduced to the backhaul networks at different points. Figure 2 illustrates the concept: three edge routers and one gateway have to prioritize and shape the traffic in order to keep the right-most backhaul link unsaturated. Inner nodes also have to collaborate in respecting priorities. Once the network elucidates how much traffic should be accepted to/from each AP, different strategies could be used to ensure endto-end QoS over the shared infrastructure: distributed QoS architectures based on DiffServ at the IP layer, or MPLS at a lower layer. In [14] the backhaul architecture satisfying all these requirements is detailed, justifying the need of a traffic control system in every node, a function that can be efficiently performed by a low-cost embedded router. Results [14] demonstrate that the proposed backhaul architecture achieves carrier-class QoS for voice and signaling traffic, while assuring the best possible quality for data traffic.

Dynamic transport network configuration. Any static solution is not adapted to reality. On one hand, the network might temporarily be able to accept more traffic than the nominal value from/to a given AP without any negative impact, provided that the edge nodes have enough information about the network state. On the other hand, the capacity of wireless links may be perturbed by weather or other environmental conditions. Additionally, nodes are likely to be powered with solar photo-voltaic systems, prone to power shortages. Beyond that, the possibility of dynamically changing parameters as a function of the network state must be examined so that either the performance is fostered or costs can be reduced. Hence, TUCAN3G has proposed dynamic mechanisms for resource allocation that take into consideration both the dynamic evolution of the state of the backhaul, and the dynamics of traffic demands [13]. The problem of dynamic optimum distribution of the resources can be cast into a convex optimization problem. Experimental results show that the backhaul architecture adopted in the platforms 
is capable to implement a distributed version of the optimization algorithm, based on local information in each node.

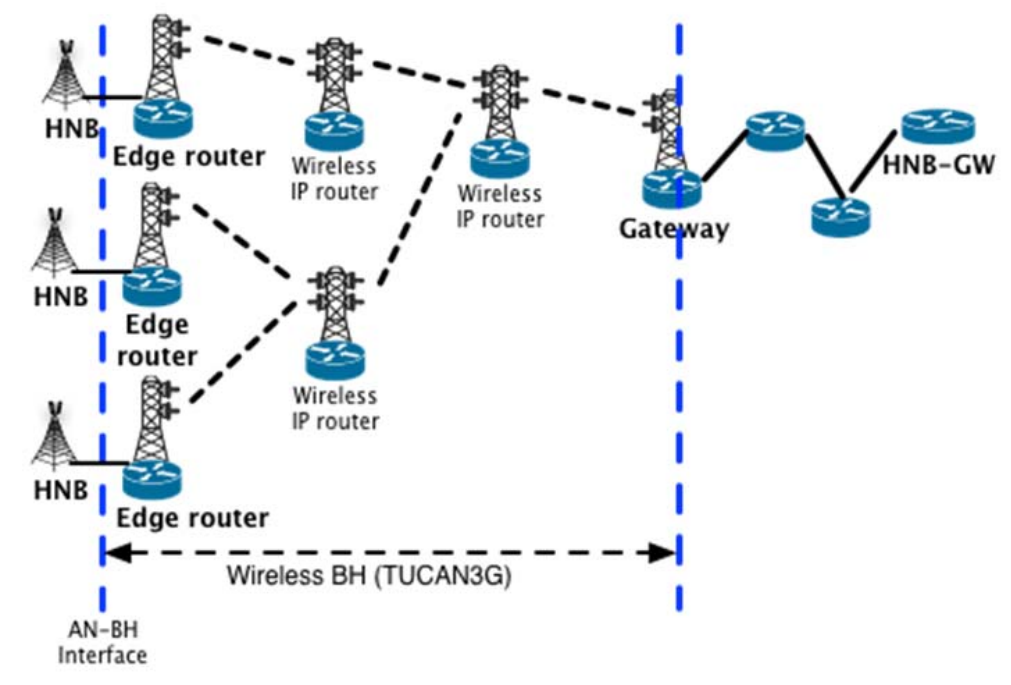

Figure 2: The architecture of the multi-hop shared backhaul in TUCAN3G networks.

Interconnection to the MNO core network. The traffic coming from/going to the rural network is exchanged with the radio network controller (RNC) residing in the MNO core network. Switching that traffic across the distribution network and the core network may arise several issues, depending on the technology chosen. The following aspects have to be considered:

- Conditions imposed by the AP manufacturer for the interconnection of the rural AP to the RNC.

- Conditions imposed by the MNO in how the traffic has to be switched between the rural network and the $\mathrm{RNC}$ in the core network.

- Considerations related to the inner architecture of the MNO's core network, which is subject to strict security protocols, and might have architectural separations, either logical or physical, in circuit switched (CS) and packet switched (PS) networks, and/or in data plane and control plane.

To cover these requirements it was necessary to create virtual interfaces on the RNC to fit the architecture of the core network. Also, point-to-point VPN links were implemented between the controller and each edge router, which differed from the usual policies of TdP. Furthermore, in order to achieve communication between the RNC 
and AP via the transport network TdP and installed heterogeneous networks, it was necessary to adopt various specific solutions and variations to the standard configurations, such as:

- Increase the maximum number of RSCP retransmissions in the RNC in order to improve packet loss tolerance.

- IPSec tunnels were implemented between each AP and RNC and enable NAT in the edge router to allow properly route traffic.

- Signaling prioritization was implemented as part of a complex process of customizing the equipment configuration of the demonstration platforms.

\section{SUSTAINABLE BUSINESS MODEL}

The previously described access and transport technologies have to be integrated into a sustainable business model. The first step is to analyze the structure of costs and compare it to conventional strategies. The analysis shows that the main difference is the backhauling deployment: MNO usually deploy a satellite backhaul for each rural community whose total ownership cost (TOC) in 5 years doubles the TOC of low-cost wireless terrestrial backhauling [14].

The second step is to analyze how this solution could be applied in a real scenario considering the characteristics, expectations and potentials of key stakeholders: consumers, MNOs, and administration. The market survey sheds the following results:

Demand side. 363 interviews were conducted in six rural populations (see Section 6). Results show that $42 \%$ of participants earn less than $\$ 140$ per month. Despite their low and variable income, $69 \%$ own a conventional mobile phone and $11 \%$ a smartphone that are used when traveling to the urban areas. They are estimated to complete an average of 20 calls per month (with cost of $\$ 0.20$ per call) and $60 \%$ of interviewed inhabitants were willing to pay over $\$ 3.6$ per month for Internet access. This figures justify to assume an average revenue per user(ARPU) of $7 \$$ per month, and a service penetration of $50 \%$.

Offer side. Large MNOs maintain a moderate-to-low interest in Peruvian rural areas. In addition to the high deployment and operating costs, the service quality established by law in rural and urban areas is similar, a requirement which is difficult to guarantee due to the time required to reach these isolated communities. If we also 
take into account that urban areas concentrate the largest volume of business, we can easily understand where large MNO investment strategy is focused. As a consequence, they are leaving a niche of opportunity for smaller MNOs or network communities willing to offer services as long as regulation allows it.

Public sector. Peruvian administration has decided to support the deployment of communications networks as a tool to promote local development and to bring administration services closer to rural population. To accomplish this objective they play a dual role. On one hand, the government administrates public funds coming from taxes applied to companies with large business volumes (like telecom operators, oil, mining, etc.) through the FITEL, and devote them to reduce inequalities between rural and urban areas by deploying new infrastructures through different mechanisms such as subsidies or loans that usually do not cover operation costs. On the other hand, the administration can act through regulation to establish incentives or to enforce MNOs to work in rural areas, to establish new quality requirements or to promote innovative approaches.

Based on this information, several business models were proposed to cover both the demand for $3 \mathrm{G}$ services and the revenue expectations of large telecommunications operators. The most relevant are compared in Figure 3:

- Satellite: a satellite backhauling per location, which is the traditional approach and is used as reference.

- Dedicated: a dedicated terrestrial backhauling based on the low-cost technologies previously proposed which would exclusively be used for $3 \mathrm{G}$ services.

- Shared: a shared terrestrial backhauling based on the low-cost technologies proposed in section 4.2 which would be shared with other services (3G, fixed Internet access, etc.).

- Existing towers: a terrestrial backhauling deployed over existing subsidized infrastructure, which would be exclusively used for $3 \mathrm{G}$ services.

The figure of merit adopted for comparison is the minimum number of inhabitants per locations that would provide a positive margin between revenue and TOC in 5 years (assuming an ARPU of $\$ 7$ and a penetration of 50\%). Results in Figure 3 show that wireless terrestrial networks can reduce the number of inhabitants required to reach the breakeven from 800 (with satellite backhauling) to 400. It is economically feasible to reach even smaller communities (around 200 inhabitants) with alternative business models based on sharing the wireless network with other services, or taking advantage of previously mentioned public funds. This analysis is based on actual 
information from our high-cost deployments, which means that TUCAN3G solution could reach even smaller communities in more accessible (but still isolated) scenarios, like the Andean region where the deployment cost is significantly lower.

Finally, it is important to note that the wireless terrestrial backhauling could be deployed by a MNO but also by a tower-rental company, a local community or a public administration. Therefore, it would be possible to combine local initiative with public support.

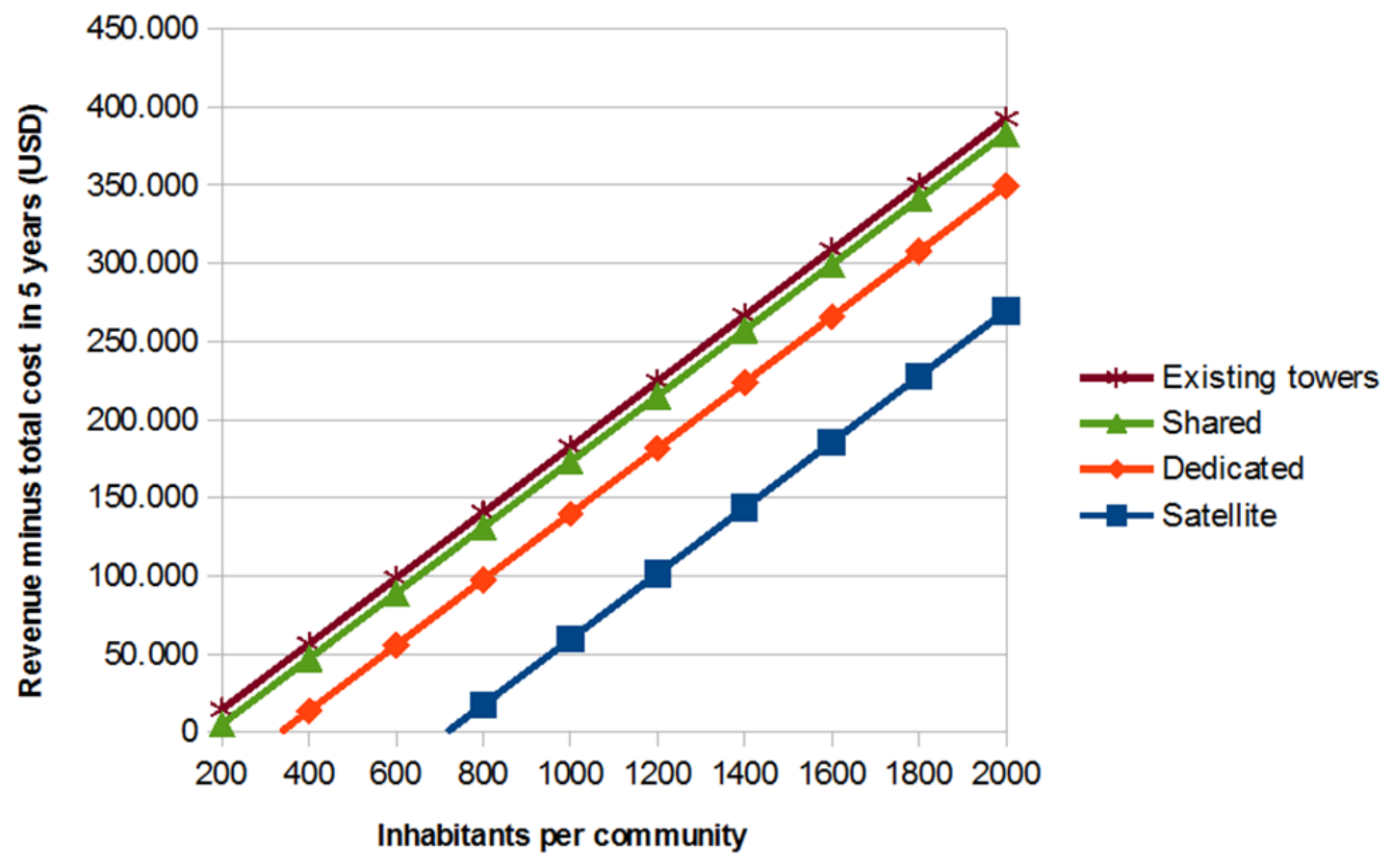

Figure 3. Revenue minus TOC in 5 years, versus number of inhabitants per community. As compared to satellite solutions, the TUCAN3G proposal generates a positive return for much smaller communities.

\section{DEMONSTRATIVE PILOTS}

In order to implement mobile services on the six target communities, TUCAN3G has deployed an access network (see table I) and a transport infrastructure. In all communities the coverage field measurements for the access network accurately confirmed the values issued by the access planning tool. The Napo network is connected to the MNO's core network through a VSAT terminal, while the second connects to the MNO's fiber optic distribution network directly in Yurimaguas city. The RNC is a NC200 (by IP.Access) installed in TdP premises in Lima.

The main components of the demonstration platform are displayed in Figure 4 and described next. 


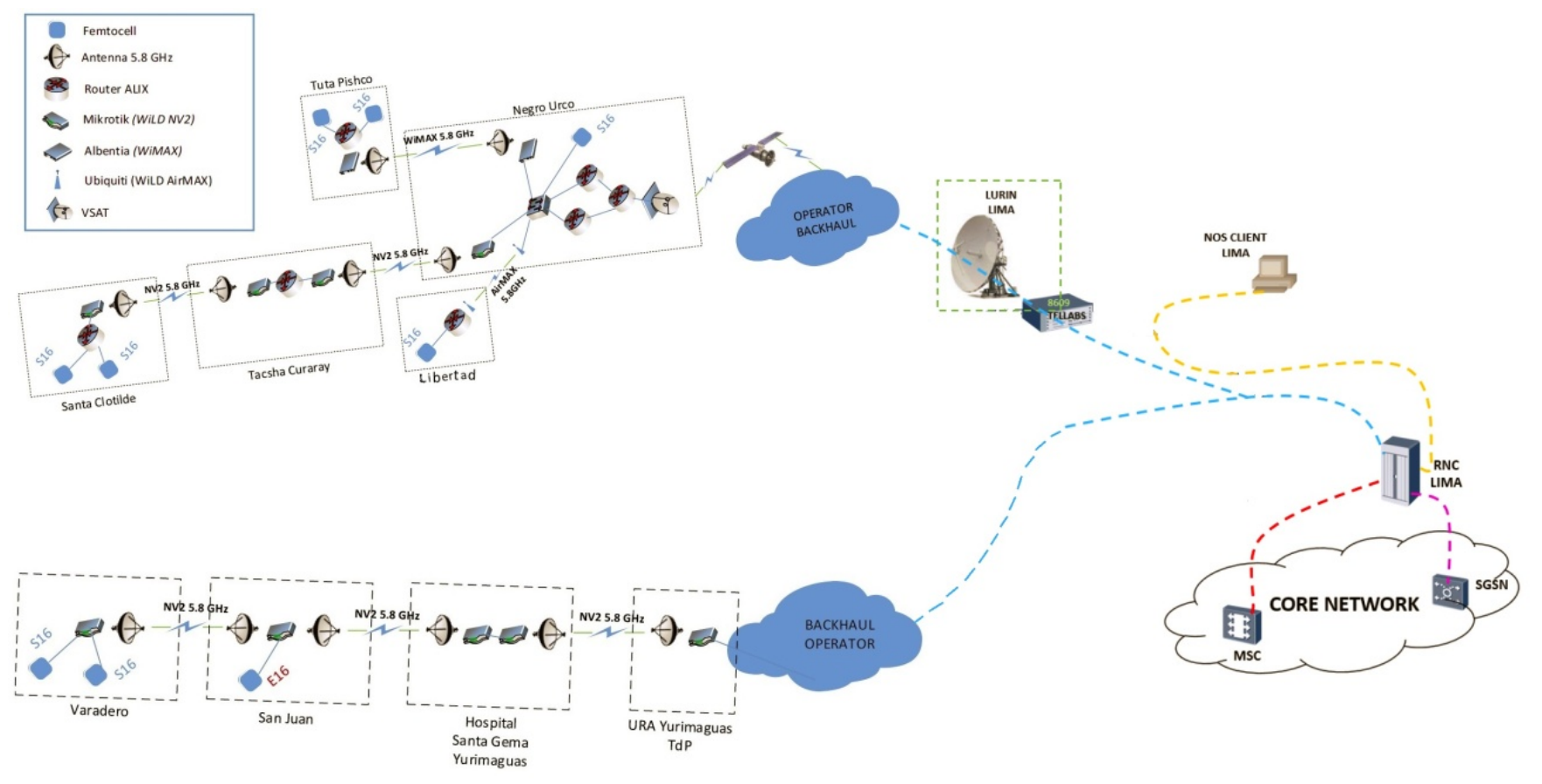

Figure 4: Network architecture for the TUCAN3G project.

Napo Network: This network consist of 6 AP and four backhaul hops that communicate via point-to-point links operated by WiMAX and WiLD routers at $5.8 \mathrm{GHz}$ placed in $70 \mathrm{~m}$ high towers. The traffic supported by the backhaul concentrates on the gateway router located in Negro Urco, which connects to the MNO's backhaul via a VSAT in Ku-band whose main NOC is located in Lima. The minimum end-to-end capacity in the Napo Network backhaul corresponds to the WiMAX link, showing a stable capacity of 3.7 Mbps for the UL and 3.7 Mbps for the DL (the symmetry may be broken to ensure more capacity in the downlink, though this has not been implemented because the available capacity exceeds what is needed according to the planning in Table I). The SISO WiLD links have shown a minimum end-to-end capacity of $4.2 \mathrm{Mbps}$ in each direction and peaks of up to $8.11 \mathrm{Mbps}$ in each direction. The satellite link has a minimum of $1.2 \mathrm{Mbps}$ capacity for the upstream and the same for the downstream, although peaks are admitted up to $1.5 \mathrm{Mbps}$ for the upstream and $2.6 \mathrm{Mbps}$ for the downstream (capacities have validated by injecting traffic with iPerf tool). The round-trip end-to-end delay between AP in the Napo network and the RNC in Lima has been measured while the network was exposed to real traffic, having obtained an average value of $630 \mathrm{~ms}$. In Tuta Pishco (WiMAX link), the delay is $60 \mathrm{~ms}$ higher due to the frame duration. Packet losses are below $1,7 \%$ and jitter below $0,2 \mathrm{~ms}$ in all links. 
Balsapuerto Network: This network consists of three AP and three MIMO WiLD point-to-point links connected to TdP Yurimaguas station, and from there to the nation-wide optic fiber network. The capacity measured end-toend across the three hops is $5 \mathrm{Mbps}$ UL and $15 \mathrm{Mbps}$ DL (measurements taken using the BW tester embedded in Mikrotik systems acting as edge routers and gateway respectively). The average round-trip end-to-end delay between femtocells and the RNC in Lima is $77 \mathrm{~ms}$. All capacities and delays obtained meet the expectations and the requirements of the access network planning. Packet losses are below $0,25 \%$ and jitter below $0,56 \mathrm{~ms}$.

Radio Network Controller: The NC200 (see Figure 5) is responsible for separating/integrating circuit switched (CS) and packet switched (PS) traffics, which are diverted from/to the MSC or SGSN, as appropriate. The RNC aggregates traffic from the AP through the Iuh interface and provides standard Iu-CS and Iu-PS interfaces to the core network, carried over IP.

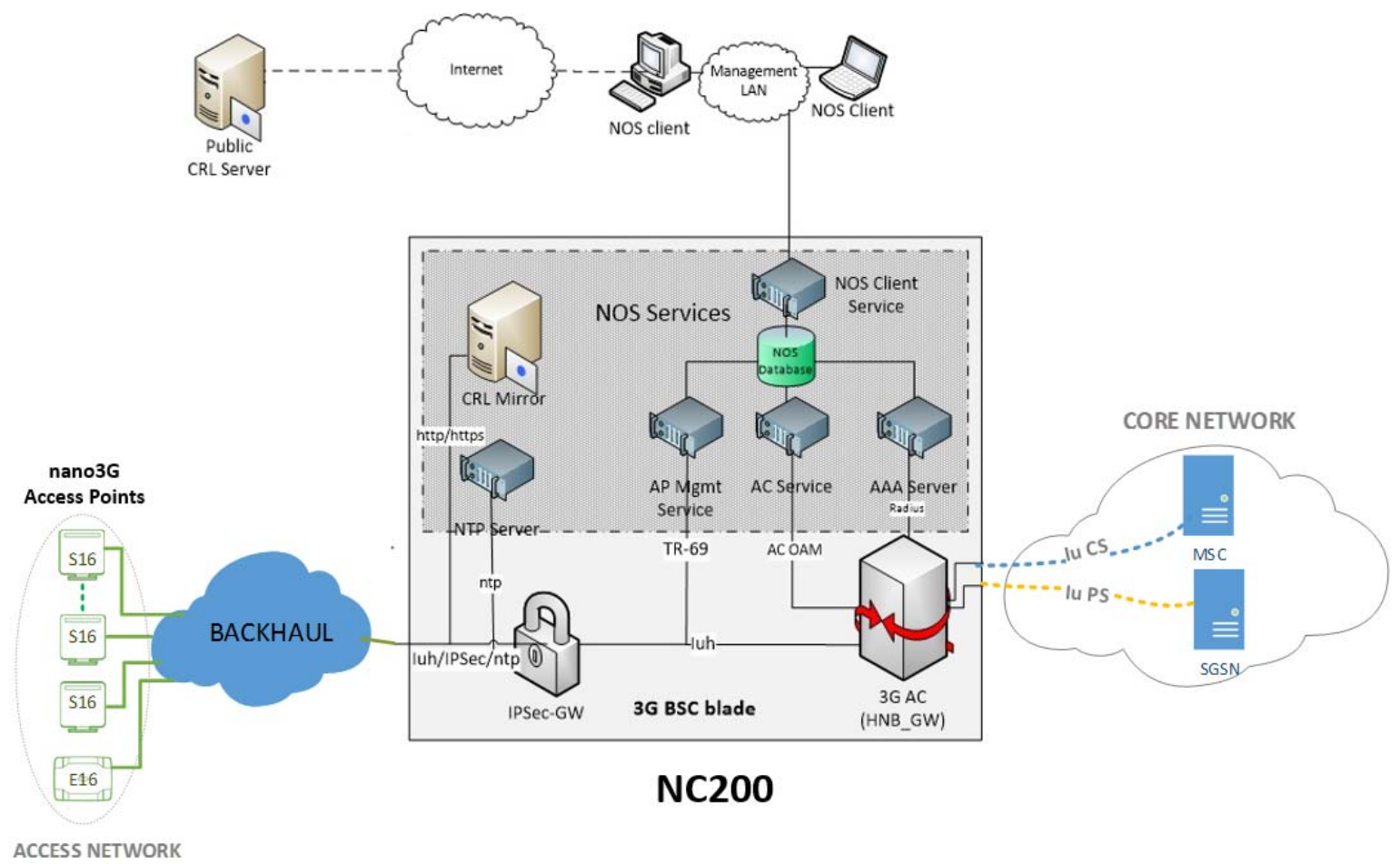

Figure 5: Radio Network Controller and its integration in the access and core networks.

From the experience of deploying the demonstration pilots some lessons can be drawn:

1) Platform operation in licensed bands. The cost of spectrum licenses is very high so it is not easy to get a permit of use in a pilot project. In our case, TdP is part of the consortium and is providing service to mobile users. Their full cooperation for spectrum use and for import of equipment has been necessary. 
2) Costs. The cost of each AP is in the range of US\$ 1,000, whereas the cost of the RNC is in the range of hundreds of thousands US\$. Clearly the deployment only makes sense if the RNC is going to provide service to many nation-wide AP. In addition, there is also a high cost for the integration of the RNC in the core of the MNO that normally involves interacting with other manufacturers. Also, our pilot demonstration is leveraging existing infrastructure (tower) that EHAS Foundation had installed in these locations for previous telemedicine projects. The size and the cost associated with the towers in the jungle (average height of 70 meters and costs above US\$ 20,000 ) is much higher than in mountain areas (about 12 meters and costs below US \$3,000).

3) Continuity of service and penalties. In many countries, the law enforces maintaining mobile service once it is launched. Moreover, in many cases, penalties for low quality of service and blackouts are the same for rural than urban areas, which discourage MNOs to participate in pilot testing or innovative projects. In TUCAN3G, TdP and the FITEL were partners of the consortium and this helped to negotiate a consensus position: should the project become economically non-viable in the long term, the operator undertakes to maintain at least the voice service.

4) The resistance or acceptance of MNOs for these deployments depends largely on the position of the public sector. The approval of legislation to facilitate the introduction of new players in the rural sector (in the form of rural mobile operator) and more flexible conditions of service delivery will help to bridge the coverage gap in these remote areas.

5) It is crucial to build mutual trust relationships with the communities: such projects require the participation and understanding of the population, their acceptance and formal approval. Usually, the expectation of the people is very high, and they take an active role in proactively reporting incidents during the works and the stabilization process of the platforms.

\section{ConCLUSIONS}

The pilot deployment is operating since October 2015, and has reached an average of 40 daily calls per location. It is believed that 70 daily calls will be reached soon and make the service sustainable.

Several international development agencies have shown interest in the TUCAN3G initiative. The Andean Development Corporation (CAF) and the Regional Government of Loreto has offered additional funds to extend 
coverage to the entire basin of the Napo River, adding another 15 locations to the pilot demonstration project. The verification of the business model in this larger sample will reinforce the findings of our study.

In conclusion, TUCAN3G has developed technology adapted to rural reality of DC. Also it has verified the technical, economic and social viability of a model providing $3 \mathrm{G}$ services alternative to the current, whereby administration, rural infrastructure MNOs and large MNOs can jointly provide coverage to remote areas usually neglected in DC.

\section{ACKNOWLEDGMENTS}

This work has been funded by the European Commission FP7 program through the project TUCAN3G (IST601102 STP), and also by Fondo de Inversión de Telecomunicaciones de Perú (FITEL). The authors acknowledge the contribution of all partners: UPC, URJC, PUCP, UCAUCA, TdP, TIWS, IPAccess, EHAs, CREPIC, FITEL and KINNO.

\section{REFERENCES}

[1] ITU Telecommunication Development Sector. "ICT Facts and Figures - The world in 2015". Available: http://www.itu.int/en/ITU-D/Statistics/Pages/facts/default.aspx.

[2]

Partnership on measuring ICT for Development. "Final WSIS Targets review achievements, challenges and the way forward". 2014. Available: http:/www.itu.int/en/ITUD/Statistics/Documents/publications/wsisreview2014/WSIS2014_review.pdf.

K. Heimerl, et al., "A longitudinal study of local, sustainable, small-scale cellular networks", Information Technologies \& International Development, Special Issue. 11(1), 2015, pp 1-9.

[4] M. Zheleva, et al. "Kwiizya: local cellular network services in remote areas", 11th Annual International Conference on Mobile Systems, Applications, and Services, June 2013, Taipei, Taiwan. 
C. Rey-Moreno, et al. "Making a community network legal within the South African regulatory framework", Seventh International Conference on Information and Communication Technologies and Development (ICTD 2015), Singapore, May 2015.

J. Simo-Reigadas et al., "Modeling and optimizing IEEE 802.11 dcf for long-distance links", IEEE Trans. Mobile Computing, Vol. 9, N. 6, 2010, pp. 881-896.

Las Tecnologías de Información y Comunicación en los Hogares: Abril-Mayo-Junio 2015. Available: http://www.inei.gob.pe/biblioteca-virtual/boletines/tecnologias-de-la-informaciontic/1/

G. Auer et al., "How much energy is needed to run a wireless network?", IEEE Wireless Communications, vol.18, no. 5, pp.40-49, October 2011.

J. Rubio, et al., "Dynamic Base Station Switch On/Off Strategies for Sustainable Wireless Networks", IEEE International Workshop on Signal Processing Advances for Wireless Communications, Toronto, Canada June 2014.

J. Rubio, et al., "User association for load balancing in heterogeneous networks powered with energy harvesting sources", IEEE Global Communications Conference, Austin, USA, December 2014.

A. G. Marques, et al. "A Decomposition method for optimal user association in cellular networks with orthogonal transmissions", IEEE Intl. Conf. on Acoustics, Speech, and Signal Processing (ICASSP), Adelaida, Australia, June 2015.

J. Rubio, et al., "A Stochastic Approach for Resource Allocation with Backhaul and Energy Harvesting Constraints", to appear in IEEE Transactions on Vehicular Technology, 10.1109/TVT.2015.2468061. "Broadband Radio Access Networks (BRAN); Broadband Wireless Access and Backhauling for Remote Rural Communities”, document TR 103 293, June 2015.

[14] J. Simo-Reigadas, et al., "Sharing low-cost wireless infrastructures with telecommunications operators to bring 3G services to rural communities", Computer Networks, Elsevier. Volume 93 Issue P2, December 2015, pp. 245-259. 


\section{BIOGRAPHIES}

Andrés Martínez-Fernández received his degrees in Telecommunications Engineer (1994) and PhD (2003) from the Polytechnic University of Madrid (Program of Biomedical Engineering and Health Technology). He is currently an associate professor in the Department of Theory of Signals and Communications, Universidad Rey Juan Carlos, Madrid. He is also a director of the EHAS Foundation. His current research interests include telemedicine and low-cost telecommunication systems for less developed region.

Josep Vidal is professor in Universitat Politècnica de Catalunya, in Spain. He has coordinated collaborative five EC-funded projects in different areas of MIMO relay communications, self-organization, cooperative transmission and heterogeneous networks, areas where he has authored +170 journal and conference papers. He served as associate editor of IEEE Transactions on Signal Processing and is member of the IEEE ComSoc Signal Processing for Communications and Electronics Technical Committee.

Francisco Javier Simó-Reigadas received the Telecommunications Engineering degree and the Ph.D degree from Polytechnic University of Madrid, Spain, in 1997 and 2007 respectively. Since 1999 he's worked in the field of ICT for development, initially as a practitioner in Africa, later as a researcher with the EHAS Foundation, and since 2005 as associate professor with the Rey Juan Carlos University. His main fields of research are broadband wireless rural networks.

Ignacio Prieto-Egido received his degree in Telecommunication Engineering from Carlos III University in Madrid. Nowadays he works as Vising Lecturer at King Juan Carlos University and is the Project Director of the EHAS Foundation. His research is mainly focused on applications of broadband wireless technologies to provide ICT services in remote areas of developing countries, and he has coordinated several projects on this issue

Adrián Agustín received the M.S. degrees in Telecommunication (00) and Electronic Engineering (02) and the Ph.D. degree (08) from Universitat Politècnica de Catalunya, Barcelona, Spain. After working at Indra-Espacio, he joined the Signal Theory and Communications department at UPC in 2002, becoming a research associate in 2008. He has participated in seven European Commission funded projects, being the latest ones TROPIC and TUCAN3G. His research interests include wireless interference management.

Juan A. Paco Fernandez is the coordinator of the Rural Telecommunications Group of the Pontifical Catholic University of Peru, the leading university in Perú. Mr. Paco is an Electronic Engineer with postgraduate studies in telecommunications and with over fifteen years of experience in management and development of ICT projects, mainly in wireless networks and WSN. Also, he is a Cisco CCNA instructor at the Cisco Local Academy inside PUCP

Álvaro Rendón is Electronics Engineer (1979) and M.Sc. in Telematics (1989) from the University of Cauca (Colombia) and Ph.D. in Telecommunications Engineering (1997) from the Technical University of Madrid (Spain). He is Full Professor at the Department of Telematics of the University of Cauca where he is also the director of the Doctoral Program in Telematics Engineering. His research interests include rural telecommunications, e-health, e-learning, and S\&T management. 

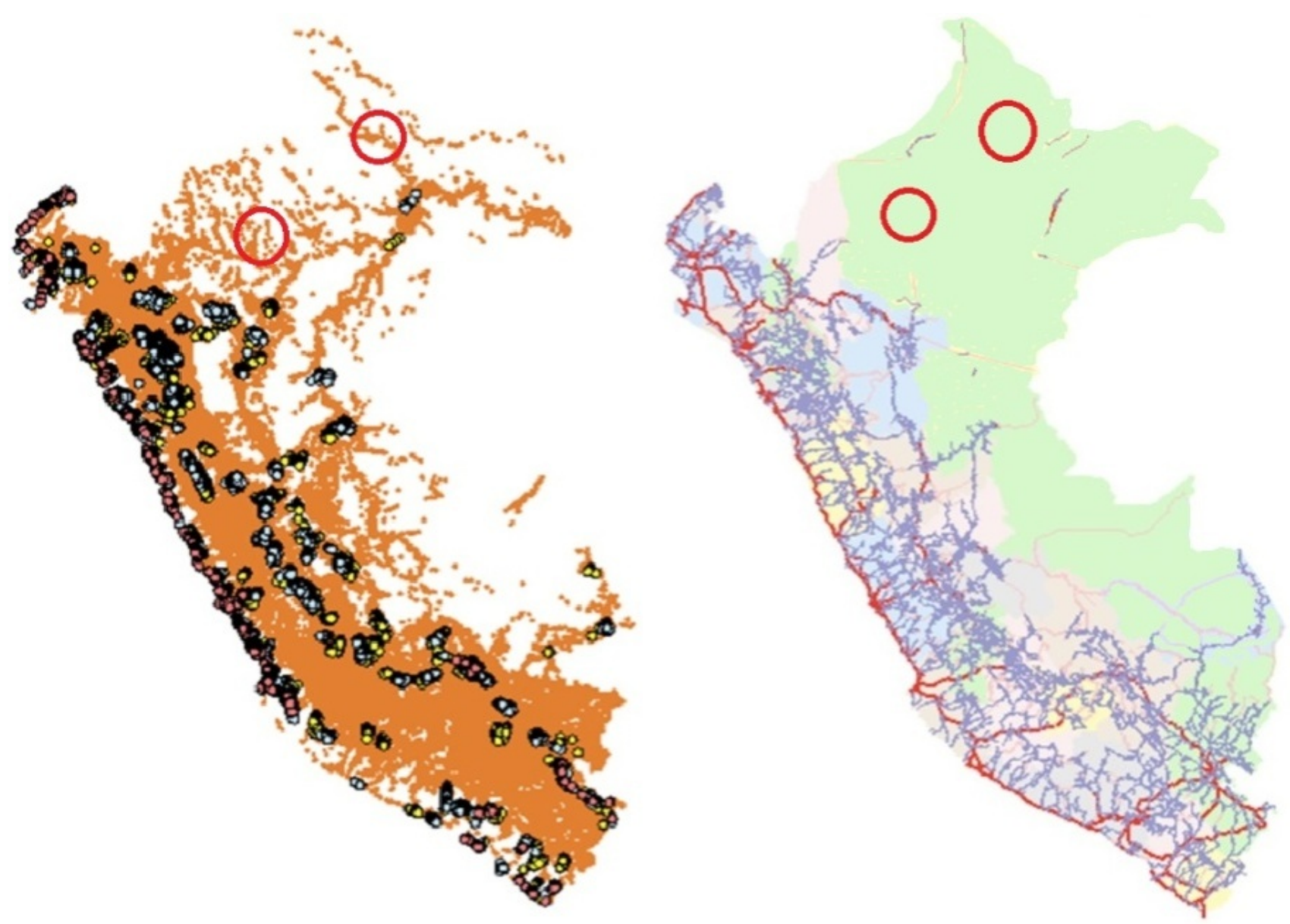

Figure 1. Base stations (left) and roads network (right) in Peru [adapted from MTC-Peru]. Red circles show the positions of the demonstrative platforms deployed by TUCAN3G. 
Table I. Access network parameters for the two networks deployed in TUCAN3G

\begin{tabular}{|c|c|c|c|c|c|c|c|c|c|}
\hline & Community & $\begin{array}{l}\text { APs from } \\
\text { ip.access }\end{array}$ & $\begin{array}{r}\text { Anten } \\
\text { configur }\end{array}$ & na & $\begin{array}{c}\text { Solar panel } \\
\text { units } \\
\left(P_{n o m}=85 \mathrm{~W}\right)\end{array}$ & $\begin{array}{l}\text { Battery units } \\
(C=1200 \mathrm{Ah} \times \mathrm{V})\end{array}$ & $\begin{array}{c}\text { Backhaul DL } \\
\text { in year } 5\end{array}$ & $\begin{array}{c}\text { Backhaul } \\
\text { UL in year } 5\end{array}$ & $\begin{array}{c}\text { Inhabitants } \\
\text { including people } \\
\text { in itinerancy }\end{array}$ \\
\hline \multirow{4}{*}{ 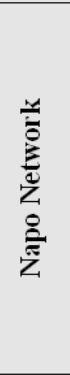 } & $\begin{array}{c}\text { Santa Clotilde } \\
2^{\circ} 29^{\prime} 22.40^{\prime \prime} \mathrm{S} \\
73^{\circ} 40^{\prime} 40.70^{\prime \prime} \mathrm{W}\end{array}$ & 2 S-Class 16 & $\begin{array}{l}\text { Gain: } \\
\text { Downtilt: } \\
\text { Height: }\end{array}$ & $\begin{array}{c}7 \mathrm{~dB} \\
10^{\circ} \\
70 \mathrm{~m} \\
\end{array}$ & 3 & 3 & $1872 \mathrm{Kbps}$ & $864 \mathrm{Kbps}$ & 3222 \\
\hline & $\begin{array}{c}\text { Negro Urco } \\
3^{\circ} 01^{\prime} 23.10^{\prime \prime} \mathrm{S} \\
73^{\circ} 23^{\prime} 31.50^{\prime \prime} \mathrm{W}\end{array}$ & 1 S-Class 16 & $\begin{array}{l}\text { Gain: } \\
\text { Downtilt: } \\
\text { Height: }\end{array}$ & $\begin{array}{l}7 \mathrm{~dB} \\
10^{\circ} \\
70 \mathrm{~m}\end{array}$ & 2 & 2 & \multirow{2}{*}{$1238 \mathrm{Kbps}$} & \multirow{2}{*}{$608 \mathrm{Kbps}$} & \multirow{2}{*}{316} \\
\hline & $\begin{array}{c}\text { Libertad } \\
3^{\circ} 1^{\prime} 41.31^{\prime \prime S} \\
73^{\circ} 22^{\prime} 40.14^{\prime \prime} \mathrm{W}\end{array}$ & $1 \mathrm{~S}-\mathrm{Class} 16$ & $\begin{array}{l}\text { Gain: } \\
\text { Downtilt: } \\
\text { Height: }\end{array}$ & $\begin{array}{l}7 \mathrm{~dB} \\
10^{\circ} \\
15 \mathrm{~m}\end{array}$ & 2 & 2 & & & \\
\hline & $\begin{array}{c}\text { Tuta Pishco } \\
3^{\circ} 06^{\prime} 31.40^{\prime \prime} \mathrm{S} \\
73^{\circ} 08^{\prime} 17.50^{\prime \prime} \mathrm{W}\end{array}$ & 2 S-Class 16 & $\begin{array}{l}\text { Gain: } \\
\text { Downtilt: } \\
\text { Height: }\end{array}$ & $\begin{array}{c}7 \mathrm{~dB} \\
10^{\circ} \\
50 \mathrm{~m}\end{array}$ & 3 & 3 & $1066 \mathrm{Kbps}$ & $557 \mathrm{Kbps}$ & 287 \\
\hline \multirow{2}{*}{ 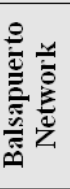 } & $\begin{array}{c}\text { Varadero } \\
5^{\circ} 42^{\prime} 49.99^{\prime \prime} \mathrm{S} \\
76^{\circ} 24^{\prime} 39.59^{\prime \prime} \mathrm{W}\end{array}$ & 2 S-Class 16 & $\begin{array}{l}\text { Gain: } \\
\text { Downtilt: } \\
\text { Height: }\end{array}$ & $\begin{array}{c}7 \mathrm{~dB} \\
10^{\circ} \\
30 \mathrm{~m}\end{array}$ & 3 & 3 & $1987 \mathrm{Kbps}$ & $892 \mathrm{Kbps}$ & 948 \\
\hline & $\begin{array}{c}\text { San Juan } \\
5^{\circ} 52^{\prime} 35.13^{\prime \prime} \mathrm{S} \\
76^{\circ} 21^{\prime} 21.73 " \mathrm{~W}\end{array}$ & 1 E-Class 24 & $\begin{array}{l}\text { Gain: } \\
\text { Downtilt: } \\
\text { Height: }\end{array}$ & $\begin{array}{c}2 \mathrm{~dB} \\
0^{\circ} \\
20 \mathrm{~m}\end{array}$ & 1 & 1 & $562 \mathrm{Kbps}$ & $285 \mathrm{Kbps}$ & 118 \\
\hline
\end{tabular}




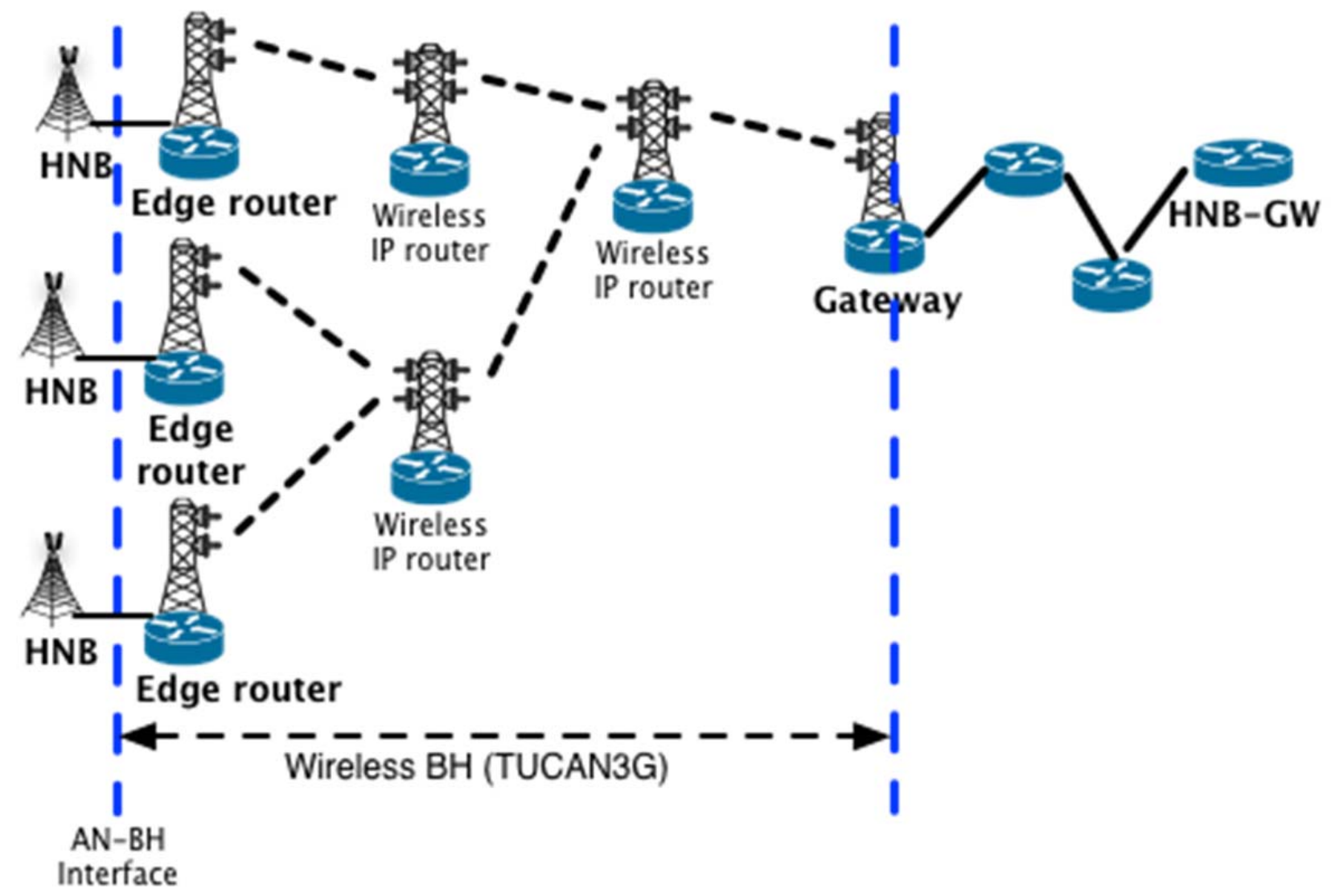

Figure 2: The architecture of the multi-hop shared backhaul in TUCAN3G networks. 


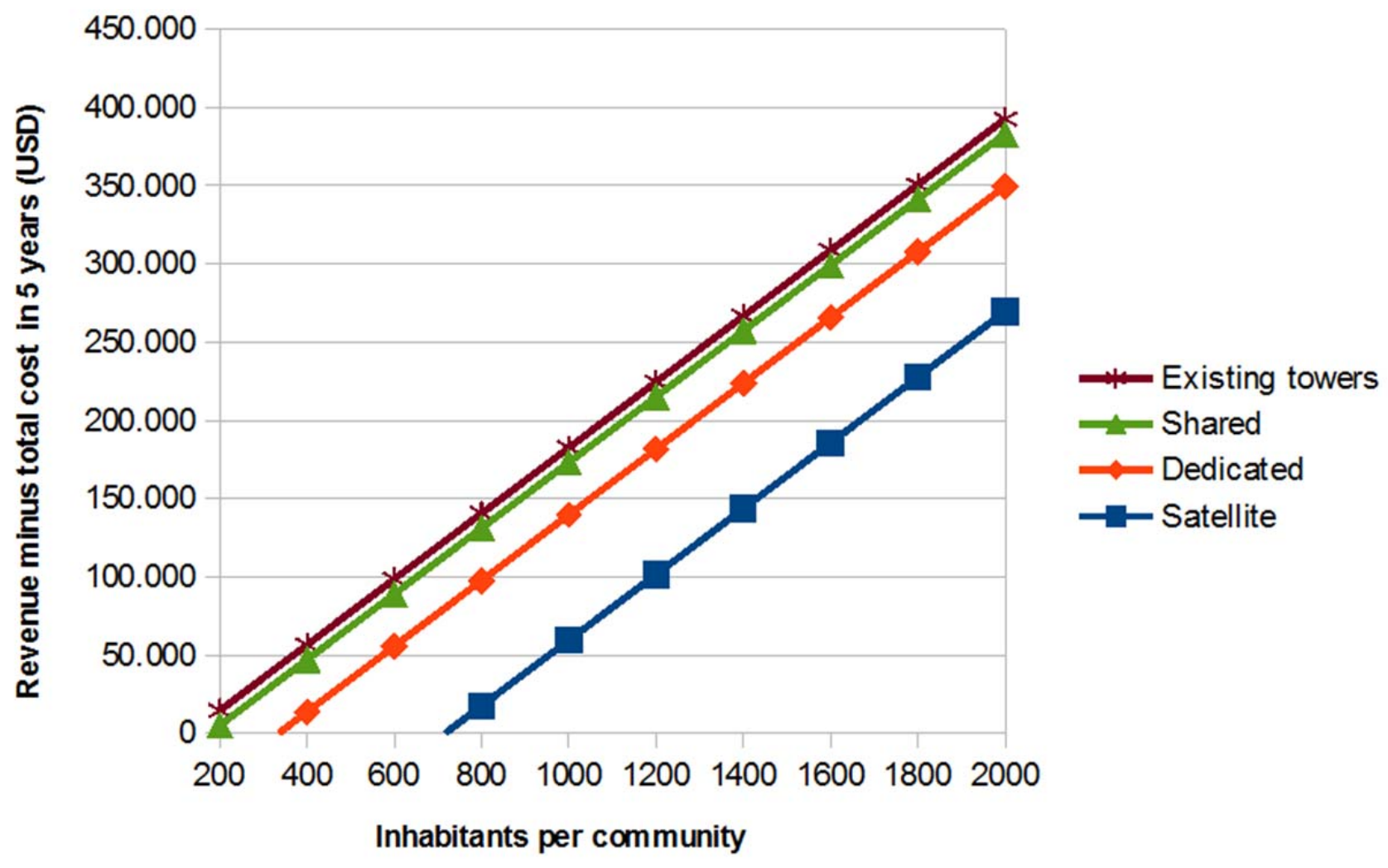

Figure 3. Revenue minus TOC in 5 years, versus number of inhabitants per community. As compared to satellite solutions, the TUCAN3G proposal generates a positive return for much smaller communities 


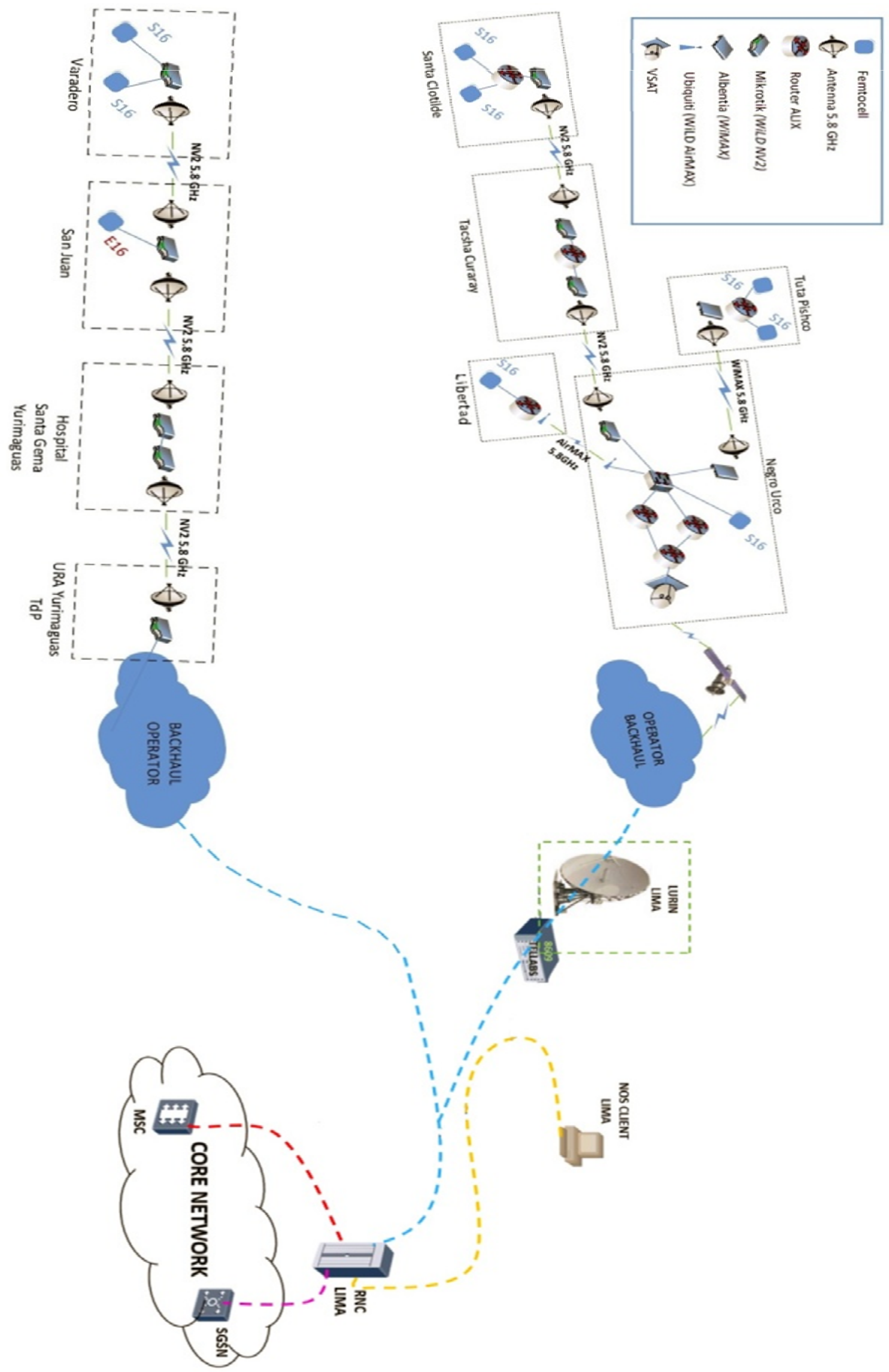

Figure 4: Network architecture for the TUCAN3G project. 


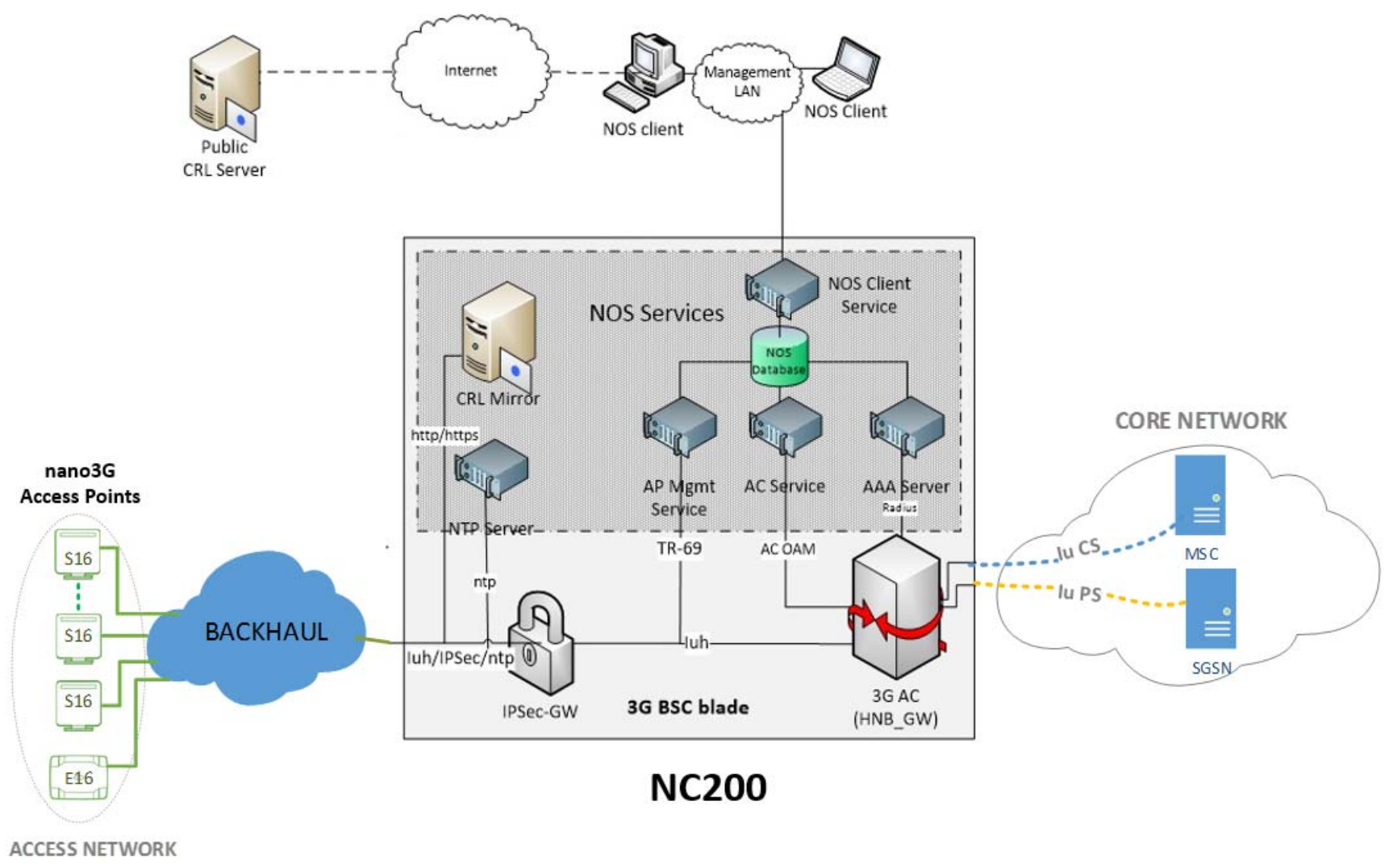

Figure 5: Radio Network Controller and its integration in the access and core networks 